\title{
Comparison between single and three portal laparoscopic splenectomy in dogs
}

Alireza Khalaj ${ }^{1,2}$, Jalal Bakhtiari ${ }^{1,3,4^{*}}$ and Amir Niasari-Naslaji ${ }^{3}$

\begin{abstract}
Background: Single incision laparoscopic surgery (SILS) is a newly growing technique to replace a more invasive conventional multiple portal laparoscopic surgery. The objective of this study was to compare single (SILS) with three portal (Conventional) laparoscopic splenectomy in dogs. Mongrel dogs $(n=18)$, weighting $15 \pm 3 \mathrm{~kg}$, were selected for this study ( $n=12$ SILS; $n=6$ conventional). The area from xiphoid to pubis was prepared under aseptic conditions in dorsal recumbency with the head down and tilted 30 degree in the right lateral position.

Pneumoperitoneum was established by $\mathrm{CO}_{2}$ using an automatic high flow pressure until achieving $12 \mathrm{~mm} \mathrm{Hg}$. Instrumentation used consisted of curved flexible-tip $5 \mathrm{~mm}$ Maryland forceps and ultracision harmonic scalpel for sealing and cutting of the vessels and splenic attachments.

Results: All dogs recovered uneventfully. The splenectomy procedure using SILS and conventional methods were significantly different in the respective operative time $(29.1 \pm 1.65$ vs. $42.0+2.69 \mathrm{~min})$ and the length of the surgical scar $(51.6 \pm 1.34 \mathrm{~mm}$ vs. $72.0 \pm 1.63 \mathrm{~mm} ; \mathrm{P}<0.001)$. There were no post-operative wound complication including inflammation, infection, hernia formation and dehiscence up to one month after surgery. Meanwhile, the conversion to open surgery or application of additional portals was not required in both approaches.

Conclusion: This study demonstrated that SILS is a safe and feasible operation and could be used as an alternative approach to three portal (Conventional) for splenectomy in dog.
\end{abstract}

\section{Background}

The application of laparoscopy, minimally invasive technique, along with its advantages and superiorities, has become an alternative approach to conventional surgery in small animal veterinary medicine [1-3]. Laparoscopy created huge changes in the field of surgery from large incisions in open surgeries to very small incisions. Within the context of laparoscopy, single incision laparoscopy is a newly growing technique to reduce the invasiveness of conventional multiple portal laparoscopic surgery. Single incision laparoscopic surgery (SILS) reduces surgical trauma and adhesion through implementing a small number and/or size of portals [4-6]. SILS is a feasible technique for different ablative and reconstructive procedures such as cholecystectomy, appendectomy and splenectomy in human [7-10].

\footnotetext{
* Correspondence: bakhtiar@ut.ac.ir

${ }^{1}$ Minimally Invasive Surgery Research Centre, Rasool Akram Hospital, Tehran University of Medical Sciences, Tehran, Iran

${ }^{3}$ Faculty of Veterinary Medicine, University of Tehran, Tehran, Iran

Full list of author information is available at the end of the article
}

Splenectomy in dog is a common operation for tumors [11]. In human, hematological immune mediated diseases, non responsive to medical treatment, ITP and hemolytic anemia are the most common indications of splenectomy $[12,13]$. The ideal indication for the laparoscopic splenectomy is an elective splenectomy in blood donor dogs to prevent transmission of hemobartonella infection [13]. Clinical and experimental researches were conducted to elaborate laparoscopic and open splenectomy $[14,15]$ resulting in the recognition of laparoscopy as a gold standard procedure for splenectomy $[16,17]$. In veterinary medicine, the feasibility of multiple portal laparoscopic splenectomy and its superiority over the conventional open technique was documented $[11,18]$. Conventional laparoscopy performed safely in laboratory animals, porcine, caprine, canine and human [18-21]. The objective of this study was to compare single (SILS) with three portal (Conventional) laparoscopic splenectomy in dogs.

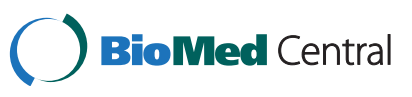




\section{Results}

Both SILS and conventional surgery were performed successfully and all dogs were recovered uneventfully. Splenic mobilization was successfully performed via a single umbilical incision. The final incision was extended for organ removal. There were significant difference $(\mathrm{P}<0.001)$ between SILS and conventional surgery in the operative time (SLIS: $29.1 \pm 1.65$ min vs Conventional $42.0 \pm 2.69 \mathrm{~min}$ ) and the length of the surgical scar (SILS: $51.6 \pm 1.34 \mathrm{~mm}$ vs Conventional: $72.0 \pm 1.63 \mathrm{~mm}$; Table 1). There was no significant difference in the length, diameter and weight of the spleen between two groups (Table 1). There were no post-operative complications including inflammation, infection, hernia formation and dehiscence up to one month after surgery. Slight and superficial rupture of spleen with very negligible and minor bleeding occurred in 4 cases (SILS: 3 dogs; Conventional: $1 \mathrm{dog}$ ) that was managed immediately without any particular requirement to perform open surgery or using additional portals to accomplish operation.

\section{Discussion}

The purpose of this study was to investigate the possibility of replacing SILS with conventional standard 3 portals laparoscopy for splenectomy in dog. Accordingly, the operative time and scar length were found to be significantly less in SILS compared to conventional method. Single portal position in SILS provided similar visualization, manipulation and exposure of splenic hilum as in conventional laparoscopy. Insertion of single umbilical portal reduced the chance of accidental injury to splenic parenchyma compared to inserting three separate portals in conventional method.

Recently, the application of SILS techniques has been described in many intra-abdominal procedures in human [22]. The goal of single port access (SPA) surgery is to minimize the incision required to perform the procedure while maintaining the surgeon's comfort [16]. To the authors' knowledge, this is the first report in using SILS for splenectomy in dog. In general, less morbidity, short length of hospital stay, less post operative pain and excellent cosmetic results were considered as advantages of SILS to the conventional multiple portals laparoscopic surgeries [23]. Moreover, SILS splenectomy seems to be safe for intra operative visualization of the splenic hilum during transection of vessels and removal of spleen [24].
The operative time is an important parameter for surgical assessment. In the present study, the operative time was shorter in SILS $(29.1 \pm 1.65 \mathrm{~min})$ than conventional method of laparoscopy ( $42.0 \pm 2.69 \mathrm{~min})$ for splenectomy in dog. Part of this difference might be due to the use of ultracision harmonic scalpel for sealing and cutting of the vessels and splenic attachments. Also, the experience of the surgeons has great impact on the outcome and operative time of this study. In one study on splenectomy using conventional laparoscopy in dog, the operative time was quite long in conventional three portals laparoscopy $(115 \pm 13.4 \mathrm{~min})$ compared to open surgery (50.2 $\pm 6.6 \mathrm{~min} ; 11)$. Apparently, experience of the surgeon could explain, in part, a long operative time. In other words, laparoscopic surgical times and complications tend to decrease with an increase in the level of the surgeon's experience, denominated learning curve [25-27].

The most time consuming part of the laparoscopic splenectomy is the time dedicated to remove spleen from the abdomen, which may be associated with the rupture of spleen. In the present study, 4 dogs (SILS: 3 dogs; Conventional: $1 \mathrm{dog}$ ) had slight and superficial rupture of spleen with negligible minor bleeding. This was managed successfully but elongated the surgical time.

\section{Conclusion}

The single incision laparoscopic surgery (SILS) could be an available, feasible and safe alternative to multiport laparoscopy for dogs undergoing elective splenectomy. It presented advantages in relation to operative time and surgical scar, without any particular complication. The use of the appropriate vessel sealer to ensure hemostasis would facilitate the procedure and decreases the operative time.

\section{Methods}

\section{Animals}

This study was approved by the ethical committee of the Faculty of Veterinary Medicine, University of Tehran (BNS717/25.07.2009). Mongrel dogs $(\mathrm{n}=18)$, weighting $15 \pm 3 \mathrm{~kg}$, were collected from Dog's Shelter House, Animal Welfare Society. Experimental dogs were kept in individual pens and received standard balanced diet throughout experiment. Dogs were returned to the Shelter House after experiment.

Table 1 Clinical and operative findings following splenectomy by single incision laparoscopic surgery (SILS; $\mathbf{n = 1 0 )}$ and conventional ( 3 portals) laparoscopy $(n=6)$ in dogs

\begin{tabular}{|c|c|c|c|c|c|}
\hline \multirow{2}{*}{$\begin{array}{c}\text { Experimental } \\
\text { groups }\end{array}$} & \multirow{2}{*}{$\begin{array}{l}\text { Operative } \\
\text { time (min) }\end{array}$} & \multirow{2}{*}{$\begin{array}{c}\text { Scar } \\
\text { length } \\
(\mathrm{mm})\end{array}$} & \multicolumn{3}{|c|}{ Spleen } \\
\hline & & & Length (mm) & Diameter (mm) & Weight (gr) \\
\hline SILS & $29.1 \pm 1.65^{a}$ & $51.6 \pm 1.34^{a}$ & $28.9 \pm 0.80^{a}$ & $10.1 \pm 0.82^{a}$ & $275.4 \pm 9.09^{a}$ \\
\hline Conventional & $42.0 \pm 2.69^{b}$ & $72.0 \pm 1.63^{b}$ & $31.2 \pm 0.87^{a}$ & $9.3 \pm 1.56^{a}$ & $288.3 \pm 6.14^{a}$ \\
\hline
\end{tabular}




\section{Anesthetic procedures}

Following 8 hours food restriction, experimental dogs received acepromazine $(0.1 \mathrm{mg} / \mathrm{kg}$; IM) and buprenorphine $(10 \mu \mathrm{g} / \mathrm{kg}$; IV) for premedication and the combination of ketamine (5.5 mg/kg; IV) and diazepam (0.2 mg/kg; IV) for induction of anesthesia. The anesthesia was maintained by inhalation of isoflurane and oxygen through anesthetic machine. Cefazolin (22 mg/kg; IV) was administered as a preoperative prophylaxis at the time of inducing anesthesia.

\section{Surgical procedures}

The area from xiphoid to pubis was prepared under aseptic condition. Dog was placed in dorsal recumbency, head down and tilted 30 degree in the right lateral position. The surgeon and cameraman both stood on the right side of the dog and monitor was placed on the opposite side. For dogs operated by SILS method $(\mathrm{n}=12), 3 \mathrm{~cm}$ midline skin incision starting from umbilicus to the caudal was made and the subcutis was reflected until revealing the linea alba. The linea alba was incised and the umbilical single portal was inserted using $5 \mathrm{~mm}$ TriPort trocar (Advanced Surgical Concepts, Wicklow, Ireland; Figure 1). For dogs operated by conventional method $(n=6), 3$ portals including umbilical, cranial and caudal were inserted, $3 \mathrm{~cm}$ apart in a straight line, using $5 \mathrm{~mm}$ trocars. In both methods, the length of umbilical incision was enlarged, with routine surgical technique, according to the size of spleen (Figure 2). Pneumoperitoneum was established by $\mathrm{CO}_{2}$ using an automatic high flow pressure until the pressure of $12 \mathrm{~mm} \mathrm{Hg}$ was achieved. A $5 \mathrm{~mm}$ in diameter 30 degree rigid telescope (29 cm length, Wolf, Germany) connected to a light source was inserted into the peritoneal cavity from the umbilical portal. The orientation of the spleen and the location of its proximal and distal poles were located initially. The $5 \mathrm{~mm}$ curved flexible-tip Maryland forceps (Carl Storz, Germany) was introduced from the cranial port and inserted through the splenic vessels at the hilum to lift the

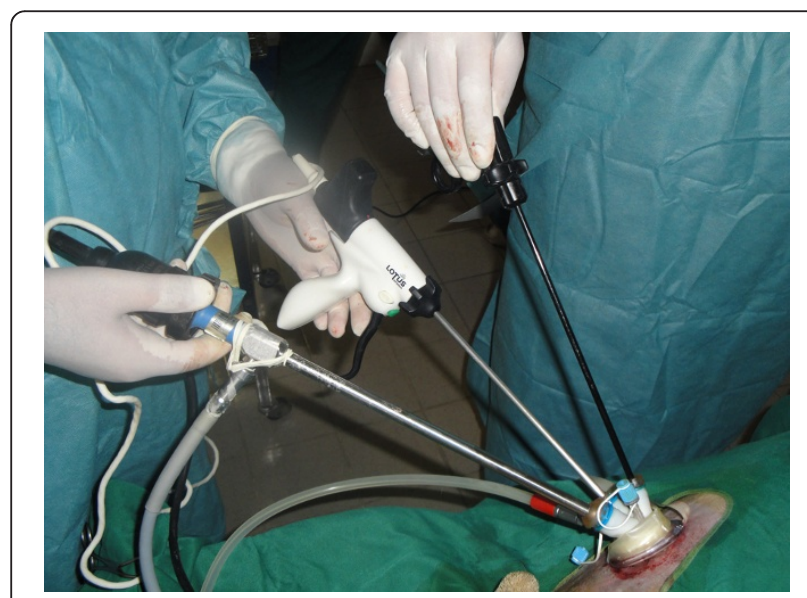

Figure 1 Single incision laparoscopic surgery (SILS).

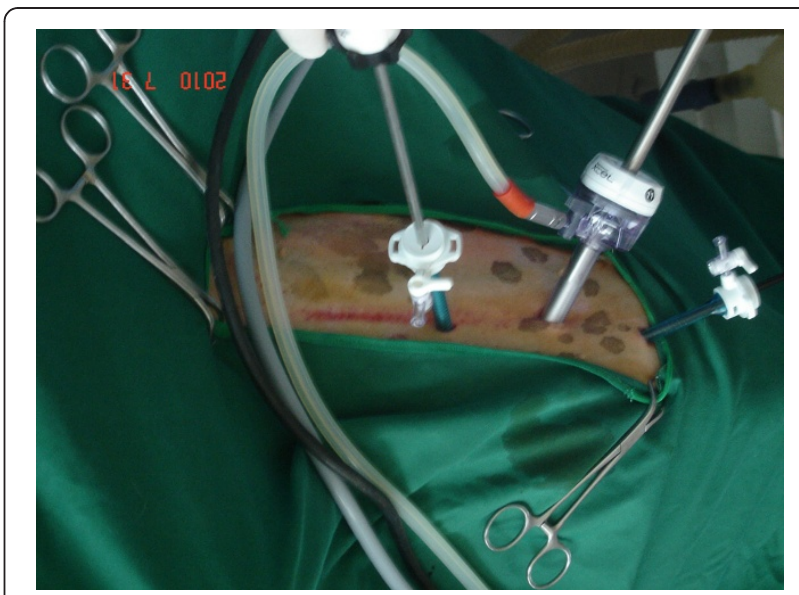

Figure 2 Conventional multiple portal laparoscopy.

spleen up from its middle part or the more accessible portion. The ultracision harmonic scalpel (lotus hand piece, SRA Developments LTD, Devon, UK), was inserted from the caudal portal to seal and cut the splenic, left gasteroepiploic and short gastric arteries, veins and gastrosplenic ligament. The location of camera and forceps were changed during the operation to maintain ergonomy for better visualization and maneuver. The direction of sealing of the splenic vessels was highly depended on the size of spleen and its orientation. Thus sealing of vessels was started either from the center of spleen and continued cranially and caudally or from the distal pole and continued toward the splenic hilus to proximal pole. Following transection of the splenic attachments, the pedicles were checked to ensure hemostasis. With the help of camera from the enlarged umbilical portal, cranial pole of the spleen was oriented and removed. Then it was grasped by Doyen forceps and exposed through the incision. It was pulled out of the abdomen very firmly to avoid fracture of the splenic parenchyma (Figure 3). The abdominal incision was closed

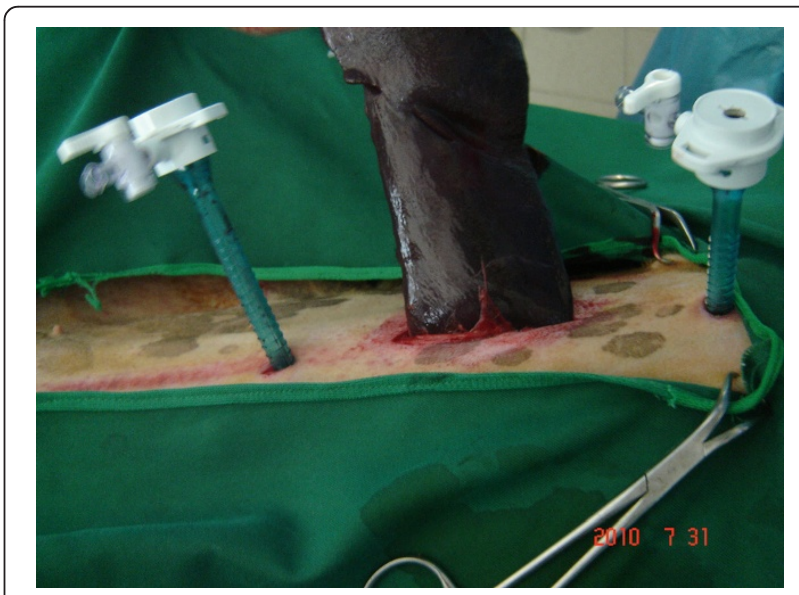

Figure 3 Removal of spleen from the abdomen. 
in a three layer routine manner. All surgeries were video recorded and the operative time, total length of the scar, weight of the spleen and its dimensions were estimated. Post operative complications were evaluated on Days 1, 3, 5,7 and 30 after surgery.

\section{Statistical analysis}

Data were analyzed using Student t-test after examining the assumptions of parametric tests using SAS/STAT [28]. Data were presented as Mean \pm SE.

\section{Competing interest}

Drs Alireza Khalaj, Jalal Bakhtiari , Amir Niasari-Naslaji as authors of this manuscript have no competing interests to disclose.

\section{Authors' contributions}

AK, JB designed the study and performed the study. JB drafted the manuscript. ANN carried out analysis and interpretation of the data and helped to draft the manuscript. All authors read and approved the final manuscript.

\section{Acknowledgements}

Authors wish to express their sincere appreciation to Dr Azin Tavakoli for some help during experiment, Research Council of the Faculty of Veterinary Medicine, University of Tehran, Center of Excellence for Veterinary Research on Indigenous Domestic Animals and Rasoul Akram Research Center of Laparoscopic Surgery for provision of financial assistance to complete this research.

\section{Author details}

'Minimally Invasive Surgery Research Centre, Rasool Akram Hospital, Tehran University of Medical Sciences, Tehran, Iran. ${ }^{2}$ Department of Surgery, Faculty of Medicine, Shahed University, Tehran, Iran. ${ }^{3}$ Faculty of Veterinary Medicine, University of Tehran, Tehran, Iran. ${ }^{4}$ Department of Surgery and Radiology Faculty of Veterinary Medicine, University of Tehran, P. O. Box: 14155-6453, Tehran, Iran.

Received: 9 September 2011 Accepted: 27 August 2012 Published: 10 September 2012

\section{References}

1. Schippers E, Tittel A, Ottinger A, Schumpelick V: Laparoscopy versus laparotomy: comparison of adhesion-formation after bowel resection in a canine model. Dig Surg 1998, 15:145-152.

2. Gamal EM, Metzger P, Szabó G, Bráth E, Petõ K, Oláh A, Kiss J, Furka I, Mikó I: The influence of intraoperative complications on adhesion formation during laparoscopic and conventional cholecystectomy in an animal model. Surg Endosc 2001, 15:873-880.

3. Freeman LJ: Veterinary Endosurgery. 1st edition. Missouri: Mosby Co; 1999:14-15.

4. Gutt CN, Oniu T, Schemmer P, Mehrabi A, Büchler MW: Fewer adhesions induced by laparoscopic surgery. Surg Endosc 2004, 18:898-906.

5. Leggett PL, Churchman-Winn R, Miller G: Minimizing ports to improve laparoscopic cholecystectomy. Surg Endosc 2000, 14:32-36.

6. Dupré G, Fiorbianco V, Skalicky M, Gültiken N, Ay SS, Findik M: Laparoscopic ovariectomy in dogs: Comparison between single portal and two portal access. Vet Surg 2009, 38:818-824.

7. Desai MM, Berger AK, Brandina R, Aron M, Irwin BH, Canes D, Desai MR, Rao PP, Sotelo R, Stein R, Gill IS: Laparoscopic single site surgery: initial hundred patients. Urology 2009, 74:805-812.

8. Froghi F, Sodergren MH, Darzi AK, Paraskeva P: Single incision laparoscopic surgery (SILS) in general surgery: A review of current practice. Surg Laparosc Endosc Percutan Tech 2010, 20:191-204.

9. Hansen EN, Munesterer OJ: Single incision laparoscopic splenectomy in a 5-year-old with hereditary spherocytosis. JSLS 2010, 14:286-288.

10. Targarona EM, Pallares JL, Balague C, Luppi CR, Marinello F, Hernández P, Martínez C, Trias M: Single incision approach for splenic diseases: a preliminary report on a series of 8 cases. Surg Endosc 2010, 24:2236-2240.
11. Stedile R, Beck CAC, Schichet F, Ferreira MP, Oliveria ST, Martens FB, Tessari JP, Bernades SBL, Oliveira CS, Santos AP, Mello FPS, Alievi MM, Muccillo MS: Laparoscopic versus open splenectomy in dogs. Pesquisa Vet Brasil 2009, 29:653-660.

12. Chapman WHH, Albrecht RJ, Kim VB, Young JA, Chitwood WR: Computerassisted laparoscopic splenectomy with the da Vinci Surgical Robot. J Laparoendosc Adv Surg Tech 2002, 12:155-159.

13. Freeman $\sqcup$ : Introduction to veterinary laparoscopy, Veterinary Endosurgery. 1st edition. Missouri: Mosby Co; 1999:192-193.

14. Aziz O, Athanasiou T, Tekkis PP, Purkayastha S, Haddow J, Malinovski V, Paraskeva P, Darzi A: Laparoscopic versus appendectomy in children: a meta-analysis. Ann Surg 2006, 243:17-27.

15. Hutter MM, Randall S, Khuri SF, Henderson WG, Abbott WM, Warshaw AL: Laparoscopic versus open gastric bypass for morbid obesity: a multicenter, prospective, risk adjusted analysis for the National Surgical Quality Improvement Program. Ann Surg 2006, 243:657-666.

16. Rottman SJ, Podolsky ER, Kim E, Kem J, Curcillo PG: Single port access (SPA) spelenctomy. JSLS 2010, 14:48-52.

17. Targarona EM, Balague C, Martinez C, Pallares L, Estalella L, Trias M: Single port access: a feasible alternative to conventional laparoscopic splenectomy. Surg Innov 2009, 16:348-352.

18. Park AE, Mckinlay R: Spleen. In Schwartz's Principles of Surgery. 8th edition. Edited by Brunicardi FC, Andersen DK, Billiar TR, Dunn DL, Hunter JG, Pollock RE. New York: McGraw-Hill; 2005:1297-1315.

19. Zhang JT, Wang HB, Liu YF, Sun YG, Shao JT, Shi J: Laparoscopic splenectomy in goats. Vet Surg 2009, 38:406-410.

20. Collard F, Nadeau ME, Carmel EN: Laparoscopic splenectomy for treatment of splenic hemangiosarcoma in a dog. Vet Surg 2010, 39: 870-872.

21. Thibault C, Mamazza J, Létourneau R, Poulin E: Laparoscopic splenectomy: Operative technique and preliminary reports. Surg EndosC 1992, 2: 248-253.

22. Romanelli JR, Earle DB: Single-port laparoscopic surgery: an overview. Surg Endosc 2009, 23:1419-1427.

23. Froghi F, Sodergren MH, Darzi AK, Paraskeva P: Single incision laparoscopic surgery (SILS) in general surgery: A review of current practice. Surg Laparosc 2010, 20:191-204.

24. Targarona EM, Balagué C, Trias M: Is the laparoscopic approach reasonable in cases of splenomegaly? Semin LaparosC Surg 2004, 11:185-190.

25. Higashihara E, Baba S, Nakagawa K, Murai M, Go H, Takeda M, Takahashi K, Suzuki K, Fujita K, Ono Y, Ohshima S, Matsuda T, Terachi T, Yoshida O: Learning curve and conversion to open surgery in cases of laparoscopic adrenalectomy and nephrectomy. J Urol 1998, 159:650-653.

26. Harkki-Siren P, Sjberg J, Kurki T: Major complications of laparoscopy: A follow-up Finnish study. Obstet Gynecol 1999, 94:94-98.

27. Fraser SA, Feldman LS, Stanbridge D, Fried GM: Characterizing the learning curve for a basic laparoscopic drill. Surg Endosc 2005, 19:1572-1578.

28. Statistical Analysis Systems (SAS): User's Guide. Version 9th edition. Cary: SAS Institute, Inc; 2005

doi:10.1186/1746-6148-8-161

Cite this article as: Khalaj et al: Comparison between single and three portal laparoscopic splenectomy in dogs. BMC Veterinary Research 2012 8:161.

\section{Submit your next manuscript to BioMed Central and take full advantage of:}

- Convenient online submission

- Thorough peer review

- No space constraints or color figure charges

- Immediate publication on acceptance

- Inclusion in PubMed, CAS, Scopus and Google Scholar

- Research which is freely available for redistribution 